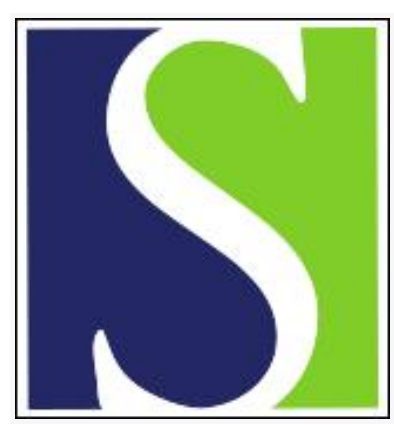

Scand J Work Environ Health 1987;13(4):343-347

https://doi.org/10.5271/sjweh.2030

Issue date: Aug 1987

Cold provocation test results from a 1985 survey of hard-rock miners in Ontario.

by Pelmear PL, Roos J, Leong D, Wong L

Affiliation: Health and Safety Support Services Branch, Ontario Ministry of Labour, Toronto, Canada.

This article in PubMed: www.ncbi.nlm.nih.gov/pubmed/3433036

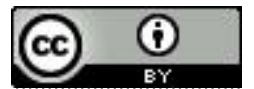




\title{
Cold provocation test results from a 1985 survey of hard-rock miners in Ontario
}

\author{
by Peter L Pelmear, MD, FFOM, CCBOM, Jaan Roos, MD, FRCPC, David Leong, PhD, PEng, CIH, \\ Lita Wong, $\mathrm{BSc}^{1}$
}

\begin{abstract}
PELMEAR PL, ROOS J, LEONG D, WONG L. Cold provocation test results from a 1985 survey of hard-rock miners in Ontario. Scand $J$ Work Environ Health 13 (1987) 343-347. A total of 143 miners, 6 ex-miners, and 42 referents from five mines in northern Ontario were examined with a cold provocation test. The skin temperatures, measured by thermocouples at the tips of the fingers and thumbs were recorded at 5 -s intervals throughout the immersion in cold water $\left(10^{\circ} \mathrm{C}\right)$ for $10 \mathrm{~min}$ and during the recovery period. The finger skin temperature was followed until $99 \%$ recovery had occurred as compared to the starting temperature. For the referents and the vibration-exposed subjects, the results by separate stage of the Taylor-Pelmear scale for hand-arm vibration syndrome were compared. There were statistically significant differences in the mean finger temperature at the $50,75,90$, and $95 \%$ recovery times between stages $0,0_{\mathrm{T}} / 0_{\mathrm{N}}$, and stages 1 through 3 combined, as well as significant differences between stages 1,2 , and 3. The mean temperature at $10 \mathrm{~min}$ and the mean hyperemia temperature for eight fingers combined were compared between the miners and referents. There were significant differences in the mean temperature at $10 \mathrm{~min}$ and in the hyperemia temperature between the referents and miners in stage $0_{\mathrm{T}} / 0_{\mathrm{N}}$, as well as between the referents and the miners in stages 1 through 3 combined. For the worst finger (defined as that with the lowest temperature at $10 \mathrm{~min}$ ) there was an increasing trend towards a lower hyperemia temperature and delay in recovery time from stage 0 to stages 2 and 3 combined. Comparison of the positive predictive values of the cold provocation test results for the worst finger supports the use of a staging of blanched fingers based on social and work interference as the grade of severity, rather than the use of a blanching index rating.
\end{abstract}

Key terms: finger skin temperature, Raynaud's phenomenon.

Objective tests to confirm the presence of Raynaud's phenomenon and grade its severity are sorely needed by clinicians, particularly in field studies. The cold provocation test has been frequently used for such purposes, and the present investigation was carried out to evaluate this use.

\section{Subjects}

A total of 227 miners or ex-miners and 60 referents were examined from five mines in northern Ontario. Ninety-six subjects were rejected from the analysis because of a history of trauma, an abnormal medical history, or an unsatisfactory clinical state. A total of 143 miners, 6 ex-miners, and 42 referents remained (table 1 ). The mean age of the referents was 34.8 years, and that of the miners 35 years. The daily exposure to vibratory tools averaged $2.1 \mathrm{~h}$. The prevalence of finger blanching by Taylor-Pelmear stages 1, 2, and 3 of the hand-arm vibration syndrome (2) was $43 \%$ among the miners, and the mean latency interval was 10.4 years.

\section{Methods}

As previously described (1), each subject was examined lying down with his body and legs completely wrapped in an elec-

\footnotetext{
1 Health and Safety Support Services Branch, Ontario Ministry of Labour, Toronto, Canada.
}

Reprint requests to: Dr P Pelmear, Ontario Ministry of Labour, Health and Safety Support Services Branch, 400 University Avenue, Toronto, Ontario M7A 1T7, Canada. tric blanket (heated to $45^{\circ} \mathrm{C}$ ) and covered with a wool overblanket except for the arm to be examined. Thermocouples were applied to the tips of the fingers and thumb with surgical tape and velcro straps, and one was placed in the armpit. When the body temperature measured by the armpit thermocouple was constant at $34-36^{\circ} \mathrm{C}$, a sphygmomanometer was placed around the wrist and inflated to $30 \mathrm{mmHg}(4 \mathrm{kPa})$ above the systolic blood pressure, and the hand was immersed in cold water. The water was maintained at a constant temperature of $10^{\circ} \mathrm{C}$ by thermostat control, and the room temperature for the study was maintained at $20-23^{\circ} \mathrm{C}$. The skin temperatures, measured by thermocouples, at the tips of the fingers and thumb were recorded at 5-s intervals throughout the immersion for $10 \mathrm{~min}$ and during the recovery period. At $5 \mathrm{~min}$ of immersion, the pressure cuff was released. At $10 \mathrm{~min}$, the hand was removed from the water and gently dried. The velcro straps were removed and replaced by dry ones. The hand was placed at rest in a horizontal position. The finger skin temperatures recorded on the tracer chart were followed until they were at $1 \%$ of the starting skin temperature. The opposite hand was then examined in the same way.

Table 1. Surveyed population.

\begin{tabular}{lccc}
\hline Group & Examined & Rejected & Accepted \\
\hline Ex-miners & 16 & 10 & 6 \\
Miners & 211 & 68 & 143 \\
Referents & 60 & 18 & $42^{\mathrm{a}}$ \\
\hline Total & 287 & 96 & 191 \\
\hline
\end{tabular}

a Includes three cases of constitutional white finger which were excluded from the analysis of the results of the cold provocation test. 


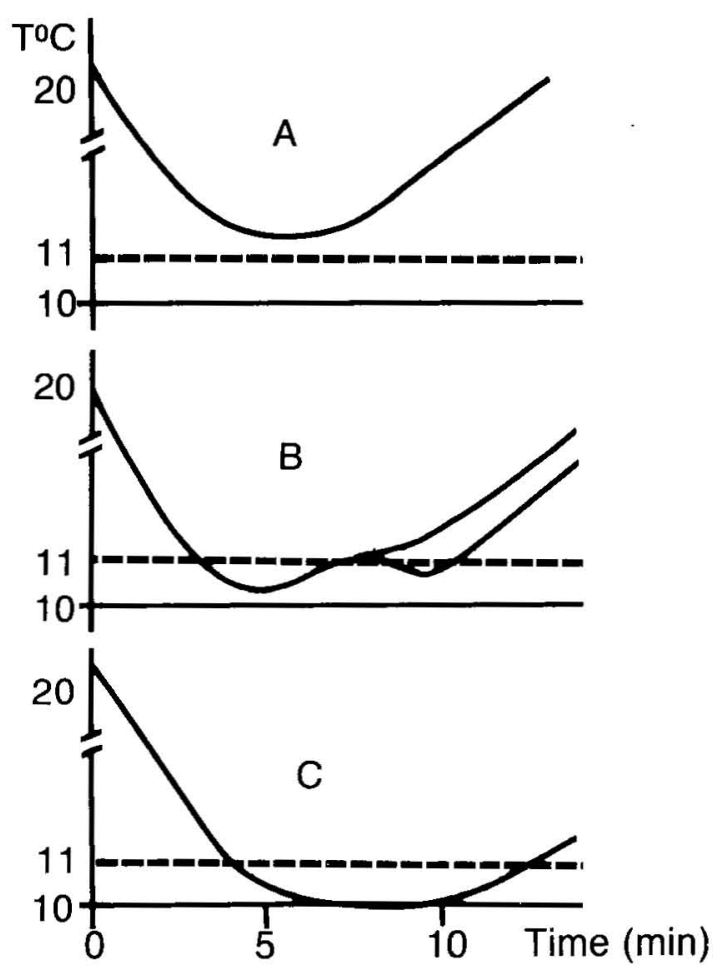

Figure 1. Skin temperature response curves (A, B, and C) determined for the subjects.

\section{Results and discussion}

The mean values of the skin temperature measurements of the referents and miners, grouped as stage $0+0_{\mathrm{T}} / 0_{\mathrm{N}}$ and stages $1-3$ of the Taylor-Pelmear scale, were compared (table 2). The differences between the groups were significant for the temperature at $10 \mathrm{~min}$ of immersion $\left(\mathrm{T}_{10}\right)$ and for the temperature at the time of hyperemia $\left(\mathrm{T}_{\mathrm{H}}\right)(\mathrm{P}<0.002)$. In addition, the differences between the groups were significant $(\mathrm{P}<0.002)$ for the length of the 50, 75, 90, and $95 \%$ recovery times.

Likewise, between stages 1,2 , and 3 there were significant differences for $\mathrm{T}_{10}$ and $\mathrm{T}_{\mathrm{H}}$ (table 3 ) and for the 75,90 , and $95 \%$ recovery times (table 3 ).

During the cold provocation, three distinct skin temperature response curves were observed which were termed A, B, and C (figure 1). The temperature for curve type $\mathrm{A}$ did not go below $11^{\circ} \mathrm{C}$. For curve type $\mathrm{C}$ it went below $11^{\circ} \mathrm{C}$ and remained there throughout the cold provocation. For curve type $\mathrm{B}$ the temperature went below $11^{\circ}$ but progressively rose with or without a hyperemic peak. It can be noted from table 4 that curve type A was the most common for all the groups but the mean of $\mathrm{T}_{10}$ was progressively lower from stage 0 to stage 2 of the Taylor-Pelmear scale. Curve type $\mathrm{C}$ could be found in every group, but it was in-

Table 2. Results of the cold provocation test of the miners (grouped according to Taylor-Pelmear stages of hand-arm vibration syndrome) and the reference group - All digits except the thumbs included.

\begin{tabular}{|c|c|c|c|c|c|c|c|c|c|c|c|c|c|c|c|}
\hline \multirow{3}{*}{ Group } & \multirow{3}{*}{$\begin{array}{l}\text { Number of } \\
\text { digits }\end{array}$} & \multicolumn{6}{|c|}{ Skin temperature ${ }^{a}\left({ }^{\circ} \mathrm{C}\right)$} & \multicolumn{8}{|c|}{ Recovery $(\mathrm{min})$} \\
\hline & & \multicolumn{2}{|c|}{$T_{5}$} & \multicolumn{2}{|c|}{$\mathrm{T}_{\mathrm{H}^{\mathrm{c}}}$} & \multicolumn{2}{|c|}{$\mathrm{T}_{10}{ }^{\mathrm{c}}$} & \multicolumn{2}{|c|}{$50 \%$ d } & \multicolumn{2}{|c|}{$75 \% d$} & \multicolumn{2}{|c|}{$90 \% \mathrm{~d}$} & \multicolumn{2}{|c|}{$95 \% d$} \\
\hline & & Mean & SD & Mean & $S D$ & Mean & SD & Mean & SD & Mean & SD & Mean & SD & Mean & SD \\
\hline \multicolumn{16}{|l|}{ Miners } \\
\hline Stage $0+0_{\mathrm{T}} / 0_{\mathrm{N}}$ & 696 & 12.2 & 1.3 & 17.1 & 4.1 & 16.5 & 4.1 & 9.3 & 1.9 & 12.8 & 3.1 & 14.8 & 4.6 & 15.9 & 5.1 \\
\hline Stages $1-3$ & 448 & 12.2 & 1.5 & 6.0 & 4.1 & 15.4 & 4.2 & 10.3 & 2.9 & 14.2 & 5.1 & 16.3 & 6.1 & 17.5 & 6.5 \\
\hline Referents & 312 & 12.3 & 1.6 & 18.4 & 4.0 & 17.6 & 3.9 & 8.9 & 1.8 & 11.7 & 1.6 & 13.4 & 2.3 & 14.5 & 2.8 \\
\hline
\end{tabular}

a $T_{5}=$ skin temperature at $5 \mathrm{~min}$ of cold provocation, $T_{H}=$ skin temperature at the time of hyperemia, $T_{10}=$ skin temperature at $10 \mathrm{~min}$ of cold provocation.

b Time needed for the skin temperature after the cold provocation to recover to $50,75,90$, and $95 \%$ of the temperature before the provocation.

c Differences between the groups at $T_{10}$ and $T_{H}$ were significant (all $P$ values $<0.0002$ )

d Differences between the groups were significant (all $P$ values $<0.002$ )

Table 3. Results of the cold provocation test of the miners in Taylor-Pelmear stages $1-3$ of the hand-arm vibration syndrome - All digits except the thumbs included.

\begin{tabular}{|c|c|c|c|c|c|c|c|c|c|c|c|c|c|c|c|}
\hline \multirow{3}{*}{$\begin{array}{l}\text { Stage of } \\
\text { hand-arm } \\
\text { vibration } \\
\text { syndrome }\end{array}$} & \multirow{3}{*}{$\begin{array}{l}\text { Number of } \\
\text { digits }\end{array}$} & \multicolumn{6}{|c|}{ Skin temperature ${ }^{a}\left({ }^{\circ} \mathrm{C}\right)$} & \multicolumn{8}{|c|}{ Recovery $(\mathrm{min})$} \\
\hline & & \multicolumn{2}{|c|}{$\mathrm{T}_{5}$} & \multicolumn{2}{|c|}{$\mathrm{T}_{\mathrm{H}^{\mathrm{c}}}$} & \multicolumn{2}{|c|}{$T_{10}{ }^{c}$} & \multicolumn{2}{|c|}{$50 \% d$} & \multicolumn{2}{|c|}{$75 \% d$} & \multicolumn{2}{|c|}{$90 \% d$} & \multicolumn{2}{|c|}{$95 \% d$} \\
\hline & & Mean & SD & Mean & SD & Mean & SD & Mean & SD & Mean & SD & Mean & SD & Mean & SD \\
\hline 1 & 240 & 12.2 & 1.5 & 17.2 & 4.2 & 16.6 & 4.2 & 9.5 & 2.5 & 12.4 & 2.6 & 14.2 & 3.7 & 15.4 & 4.3 \\
\hline 2 & 200 & 12.2 & 1.5 & 14.7 & 3.6 & 14.1 & 3.7 & 11.2 & 3.1 & 16.0 & 6.3 & 18.3 & 7.3 & 19.6 & 7.6 \\
\hline 3 & 8 & 12.0 & 1.2 & 11.7 & 1.3 & 11.1 & 1.4 & 11.3 & 1.5 & 23.1 & 4.7 & 26.1 & 4.6 & 27.4 & 4.8 \\
\hline
\end{tabular}

a $T_{5}=$ skin temperature at $5 \mathrm{~min}$ of cold provocation, $T_{H}=$ skin temperature at the time of hyperemia, $T_{10}=$ skin temperature at $10 \mathrm{~min}$ of cold provocation.

b Time needed for the skin temperature after the cold provocation to recover to $50,75,90$, and $95 \%$ of the temperature before the provocation.

c Differences were significant between stages 1,2 , and 3 (all $P$ values $<0.0002$ ).

d Differences were significant between stages 1,2 , and 3 (all $P$ values $<0.005$ ). 
dicative of latent, as well as actual, vasospastic disease and was more frequently associated with the exposed subjects.

A finger blanching index rating $(1,3$, and 6 for blanching of the distal interphalangeal, middle interphalangeal, and metacarpophalangeal joints of the fingers, respectively) was used for all the miners in stages 1 through 3 of the Taylor-Pelmear scale. This rating, when compared with the stage grading, could not differentiate stage 2 from stage 3 . Table 5 compares the mean of the $T_{H}$ and $T_{10}$ of the miners with different ratings. Both the $T_{10}$ and $T_{H}$ decreased as the finger blanching index ratings increased, and significant differences were noted between ratings 0 and 3,0 and 6 , and 1 and 6 . The recovery times increased with the index ratings (table 5) at 75, 90, and $95 \%$
Table 4. Mean of the skin temperatures of the miners in TaylorPelmear stages $0,0_{T} / 0_{N}, 1$, and 2 of the hand-arm vibration syndrome and the reference group after $10 \mathrm{~min}$ of cold provocation $\left(T_{10}\right)$ according to the type of response curve - All digits except the thumbs included.

\begin{tabular}{|c|c|c|c|c|c|c|}
\hline \multirow{3}{*}{ Group } & \multicolumn{6}{|c|}{ Response curve ${ }^{a}$} \\
\hline & \multicolumn{2}{|c|}{ Type A } & \multicolumn{2}{|c|}{ Type B } & \multicolumn{2}{|c|}{ Type C } \\
\hline & $\begin{array}{l}\text { Percent- } \\
\text { age of } \\
\text { group }\end{array}$ & $T_{10}$ & $\begin{array}{l}\text { Percent- } \\
\text { age of } \\
\text { group }\end{array}$ & $T_{10}$ & $\begin{array}{l}\text { Percent- } \\
\text { age of } \\
\text { group }\end{array}$ & $\mathrm{T}_{10}$ \\
\hline \multicolumn{7}{|l|}{ Miners } \\
\hline Stage 0 & 85 & 17.2 & 11 & 15.2 & 4 & 10.4 \\
\hline Stage $0_{T} / 0_{\mathrm{N}}$ & 76 & 17.4 & 16 & 13.5 & 8 & 10.3 \\
\hline Stage 1 & 82 & 17.4 & 10 & 15.5 & 8 & 10.5 \\
\hline Stage 2 & 61 & 16.1 & 9 & 12.8 & 30 & 10.5 \\
\hline Referents & 85 & 18.0 & 14 & 15.7 & 1 & 10.5 \\
\hline
\end{tabular}

a Type $\mathrm{A}=$ temperature did not go below $11^{\circ} \mathrm{C}$, type $\mathrm{B}=$ temperature went below $11^{\circ} \mathrm{C}$ but progressively rose with or without a hyperemic peak, type $\mathrm{C}=$ temperature went below $11^{\circ} \mathrm{C}$ and remained there.

Table 5. Results of the cold provocation test of the miners in Taylor-Pelmear stages $1-3$ of the hand-arm vibration syndrome according to their finger blanching index rating - All digits except the thumbs included.

\begin{tabular}{|c|c|c|c|c|c|c|c|c|c|c|c|c|c|c|c|}
\hline \multirow{3}{*}{$\begin{array}{l}\text { Finger } \\
\text { blanching }\end{array}$} & \multirow{3}{*}{$\begin{array}{l}\text { Number of } \\
\text { fingers }\end{array}$} & \multicolumn{6}{|c|}{ Skin temperature ${ }^{\mathrm{a}}\left({ }^{\circ} \mathrm{C}\right)$} & \multicolumn{8}{|c|}{ Recovery $^{\mathrm{b}}$ (min) } \\
\hline & & \multicolumn{2}{|c|}{$\mathrm{T}_{5}$} & \multicolumn{2}{|c|}{$\mathrm{T}_{\mathrm{H}^{\mathrm{C}}}$} & \multicolumn{2}{|c|}{$\mathrm{T}_{10}{ }^{\mathrm{d}}$} & \multicolumn{2}{|c|}{$50 \% \mathrm{e}$} & \multicolumn{2}{|c|}{$75 \% \mathrm{e}^{\mathrm{e}}$} & \multicolumn{2}{|c|}{$90 \%$ e } & \multicolumn{2}{|c|}{$95 \%$ e } \\
\hline & & Mean & SD & Mean & SD & Mean & SD & Mean & SD & Mean & SD & Mean & SD & Mean & SD \\
\hline $\begin{array}{l}0 \\
1 \\
3 \\
6\end{array}$ & $\begin{array}{r}173 \\
71 \\
125 \\
79\end{array}$ & $\begin{array}{l}12.2 \\
12.5 \\
12.1 \\
12.2\end{array}$ & $\begin{array}{l}1.6 \\
1.6 \\
1.3 \\
1.2\end{array}$ & $\begin{array}{l}16.8 \\
16.2 \\
15.5 \\
14.9\end{array}$ & $\begin{array}{l}4.3 \\
4.0 \\
3.8 \\
4.0\end{array}$ & $\begin{array}{l}16.2 \\
15.6 \\
15.0 \\
14.2\end{array}$ & $\begin{array}{l}4.3 \\
4.2 \\
3.8 \\
4.1\end{array}$ & $\begin{array}{r}9.7 \\
10.7 \\
10.5 \\
10.9\end{array}$ & $\begin{array}{l}2.7 \\
3.5 \\
2.7 \\
2.9\end{array}$ & $\begin{array}{l}13.0 \\
14.3 \\
14.8 \\
15.8\end{array}$ & $\begin{array}{l}3.4 \\
5.0 \\
6.3 \\
5.7\end{array}$ & $\begin{array}{l}15.1 \\
16.1 \\
17.0 \\
17.9\end{array}$ & $\begin{array}{l}4.5 \\
5.8 \\
7.6 \\
6.5\end{array}$ & $\begin{array}{l}16.3 \\
17.2 \\
18.3 \\
19.0\end{array}$ & $\begin{array}{l}5.1 \\
6.0 \\
7.9 \\
6.8\end{array}$ \\
\hline
\end{tabular}

a $0=$ no blanching, $1=$ blanching of the distal interphalangeal joint, $3=$ blanching of the middle interphalangeal joint, $6=$ blanching of the metacarpophalangeal joint.

b Time needed for the skin temperature after the cold provocation to recover to $50,75,90$, and $95 \%$ of the temperature before the provocation.

c $\mathrm{T}_{5}=$ skin temperature after $5 \mathrm{~min}$ of coid provocation, $\mathrm{T}_{\mathrm{H}}=$ skin temperature at the time of hyperemia, $\mathrm{T}_{10}=$ skin temperature after $10 \mathrm{~min}$ of cold provocation.

d Differences were significant between ratings $0-3,0-6$, and $1-6$ (all $P$ values $<0.05$ ).

e Differences were significant between ratings $0-3$ and between $0-6$ (all $P$ values $<0.02$ ).

of skin temperature recovery, and the differences were significant between the 0 and 3 and the 0 and 6 ratings.

The results of the cold provocation test, grouped by the Taylor-Pelmear stage of hand-arm vibration syndrome and by the finger blanching index rating, were further analyzed with reference to the worst finger, defined as that with the lowest $T_{10}$. The mean temperatures for the worst finger are compared in table 6 by stage, and a progressive lowering of temperatures for $T_{10}$ and $T_{H}$ can be noted by stage. Included in table 6 are reference means for temperatures by stage, derived by rounding the figures to the nearest $0.5^{\circ} \mathrm{C}$ and incorporating appropriate limits to differentiate the stages. Table 7 similarly shows the mean temperatures and reference means for skin temperature at the 50 and $75 \%$ recovery times. The mean temperatures and reference means for the worst finger with respect to the extent of finger blanching (ie, the blanching index) were determined and are shown in table 8 , along with the mean skin temperatures for the 50 and $75 \%$ recovery times. It can be seen that there was a progressive decrease in temperature for $T_{10}$ and $T_{H}$, but the increases in recovery times were less consistent.
Table 6. Results for the "worst" finger, ie, that with the lowest temperature at 10 min of cold provocation $\left(T_{10}\right)$, of the miners (grouped by Taylor-Pelmear stage of the hand-arm vibration syndrome) and the reference group in comparison to reference values (derived by rounding the figures to the nearest $0.5^{\circ} \mathrm{C}$ and incorporating appropriate limits to differentiate the various stages of the syndrome).

\begin{tabular}{|c|c|c|c|c|c|c|}
\hline \multirow{3}{*}{ Group } & \multirow{3}{*}{$\begin{array}{c}\text { Number of } \\
\text { workers }\end{array}$} & \multicolumn{4}{|c|}{ Skin temperature $\left({ }^{\circ} \mathrm{C}\right)$} & \multirow{3}{*}{$\begin{array}{l}\text { Reference } \\
\text { mean }\left({ }^{\circ} \mathrm{C}\right)\end{array}$} \\
\hline & & \multicolumn{2}{|c|}{$\mathrm{T}_{\mathrm{H}}{ }^{\mathrm{a}}$} & \multicolumn{2}{|c|}{$T_{10}$} & \\
\hline & & Mean & $S D$ & Mean & SD & \\
\hline \multicolumn{7}{|l|}{ Miners } \\
\hline $\begin{array}{l}\text { Stage } 0 \\
\text { Stage } 0_{\mathrm{T}} 10_{\mathrm{N}}\end{array}$ & $\begin{array}{l}58 \\
29\end{array}$ & $\begin{array}{l}13.8 \\
13.9\end{array}$ & $\begin{array}{l}2.4 \\
3.0\end{array}$ & $\begin{array}{l}13.0 \\
13.3\end{array}$ & $\begin{array}{l}2.1 \\
3.0\end{array}$ & 13.5 \\
\hline Stage 1 & 30 & 13.6 & 2.6 & 13.0 & 2.1 & 13.0 \\
\hline Stage 2 & 25 & 11.7 & 1.7 & 11.2 & 1.7 & 11.0 \\
\hline Stage 3 & 1 & 10.2 & & 10.0 & & 10.0 \\
\hline Referents & 39 & 15.0 & 2.8 & 14.2 & 2.6 & 14.5 \\
\hline
\end{tabular}

a Skin temperature at the time of hyperemia.

The reference means by the Taylor-Pelmear stage of the hand-arm vibration syndrome and by the finger blanching index were used to determine the sensitivity and specificity of the cold provocation test. The sensitivity refers to the proportion of individuals with the hand-arm vibration syndrome, according to the Tay- 
positives and false positives). The results have been tabulated by stage in table 9 and by finger blanching index in table 10. The comparisons are made both for the exposed workers and for all the workers combined. It shows that the cold provocation test is sensitive and specific enough to verify vasospastic disease, as well as finger blanching. However, the positive predictive values for grouping by stage (36-46 \% for immersion reference temperatures, $42-63 \%$ for recovery times) are somewhat better than grouping by blanching index ( $26-33 \%$ for immersion reference temperature and $37-54 \%$ for recovery times).

\section{Conclusions}

The cold provocation test, as described and used in this investigation, has proved to be a feasible and practical test for use in field surveys of vibration-exposed workers.
In assessments of the results of a cold provocation test, the $T_{H}$ and $T_{10}$ of the worker's worst finger and the times at 50 and $75 \%$ of skin temperature recovery should be compared with reference means. The test results will help to confirm the diagnosis of Raynaud's phenomenon and the verification of the stage of the hand-arm vibration syndrome. Since the positive predictive value of the cold provocation test is lower with the blanching index, grading the severity of the handarm vibration syndrome by such means as the TaylorPelmear scale used in the present study is preferable.

\section{References}

1. Pelmear PL, Taraschuk I, Leong D, Wong L. Cold water immersion test in hand-arm vibration exposed. J Low Freq Noise Vib (1985): 3, 89-92.

2. Taylor W, Pelmear PL. Introduction. In: Taylor W, Pelmear PL, ed. Vibration white finger in industry. Academic Press, London 1975, pp XVII-XXII. 